\title{
Free Convective Flow of Water/Ethylene Glycol Based Micropolar Nanofluid Over a Shrinking Sheet
}

\author{
Shobha Poovani Jeevandhar ${ }^{1(\mathbb{D})}$, Vidya Kedla ${ }^{1}{ }^{(\mathbb{D})}$, Neeraja Gullapalli ${ }^{2}{ }^{(\mathbb{D})}$, Sravan Kumar Thavada ${ }^{3, * \mathbb{C}}$ \\ 1 Department of Mathematics, Shri Dharmasthala Manjunatheshwara College of Engineering \& Technology, Ujire- \\ 574240, Karnataka, India; ssdhegde1@gmail.com (S.P.J.); vidyasomayaji@gmail.com (V.K.); \\ 2 Department of Mathematics, M S Ramaiah Institute of Technology, Bangalore-560 054, Karnataka, India.; \\ gneerajamaths@gmail.com (N.G.); \\ 3 Department of Mathematics, SoAS, REVA University, Bangalore-560 064, Karnataka, India; \\ thavadasravankumar@gmail.com (S.K.T.); \\ * Correspondence: thavadasravankumar@gmail.com;
}

Scopus Author ID 56872884700

Received: 12.12.2020; Revised: 18.01.2021; Accepted: 22.01.2021; Published: 30.01.2021

\begin{abstract}
In this article, the free convective micropolar nanofluid was investigated over a shrinking sheet in the presence of a heat source by tacking into the water/ethylene glycol-based nanofluid account. The physical problem is first modeled. Under the assumptions of Boussinesq's approximation, the governing equations are reduced into non-linear PDEs. The combined non-linear PDEs representing momentum and non-homogeneous heat equations were reduced to a series of regular non-linear differential equations with appropriate similarity transformations. By applying the Runge-Kutta procedure followed by the Shooting technique, the transformed equations are then solved. Via the diagrams, the impact of related parameters characterizing the flow was presented and then addressed. It is observed that volumetric fraction has a substantial influence on the velocity profile and also induces a decrease in the boundary layer because water-based nanofluid has high thermal conductivity relative to Ferro nanofluid based on ethylene glycol.
\end{abstract}

Keywords: MHD; micropolar fluid; thermal radiation; nanofluids; ethylene glycol.

(c) 2020 by the authors. This article is an open-access article distributed under the terms and conditions of the Creative Commons Attribution (CC BY) license (https://creativecommons.org/licenses/by/4.0/).

\section{Introduction}

In recent years, boundary layer flows with effective heat transfer over a shrinking surface have drawn further interest due to their substantial technical processes such as polymer processing, fuel cells, paper making, batteries, fiber spinning, crystal growing, glass sheet manufacturing, textile manufacturing, cooling of metal sheets in a cooling bath, and various other cooling ponds. Applying the newly established field of nanotechnology will solve these challenges. In recent years, due to potential applications in diverse fields such as improved coolants in heat exchangers, nuclear and electronic reactors, safer surgery, cancer therapy, lubricants, solar collectors, boilers, and microchannel heat sinks, nanofluid science has paid attention to research. These fluids are often inevitably found in cars, transformers, waste heat disposal equipment designs, and several electronic devices required in the military field. Akilu and Narahari [1] explored nanofluid flow's effects and the isothermal vertical plate with heat generation. The governing equations are solved by the method of Keller-box finitedifference. Three parameters governing the transport mechanism, namely Brownian motion, thermophoresis parameter, Lewis number, were defined by their similarity analysis. Akmal et al. [2] found that an increase in thermal conductivity of about 60 percent can be achieved for a 
nanofluid consisting of water and 5 percent vol. in the experimental work. It was also shown by Bhargava and Rani [3] that the thermal conductivity of oil-based nanofluids improved by twofold when a small number of nanotubes (less than 1 vol. \%) were added. The boundary layer movement of the nanofluid past a vertical plate was numerically analyzed [4-6]. They observed that the skin friction and Sherwood number decreased for Brownian motion by analyzing different physical parameters' effects. Choi and Eastman [7] first proposed nanofluid use, developing a mechanism to increase the rate of heat transfer by suspending metallic nanoparticles in traditional heat transfer fluids. Das [8] has investigated the impact of channel corrugation on the improvement of heat transfer. Das et al. [9] observed the study and recommendations of nanofluids. They found that the $\mathrm{Cu}$-water nanofluid's temperature distribution is comparatively lower than that of the Ag-water nanofluid. The same author researched the improvement of thermal conductivity for water-based nanofluids containing nanoparticles of $\mathrm{CuO}$ and $\mathrm{MgO}$.

Recent manufacturing methods are distinguished by the use of new materials that Newtonian fluids do not explain. A variety of non-Newtonian models have been proposed for this purpose. Among these models, Eringen [10] introduced micropolar fluids. Boundary layer flows of a non-Newtonian fluid over a stretching sheet are often relevant from the engineering point of view; they are commonly applicable in extrusion processes, wire drawing, manufacturing of glass fiber, biological fluid movement, and food processing, etc. In view of the value of these implementations, numerous scholars [11-15]. Khan et al. [16] have studied the steady mixed convection boundary layer flow from a vertical cone frustum in water-based nanofluids. Ferrofluid convection in a cavity heated from below in the presence of an external magnetic field is analyzed numerically by Kumar et al. [17] using the Lattice Boltzmann technique. The three-dimensional magnetohydrodynamic rotating water-dependent nanofluid containing $\mathrm{Cu}$ and $\mathrm{Ag}$ nanoparticles was stated by Kumaresan and Kumar [18]. They investigated the micropolar fluid with different physical effects. Because of its significance in many technical applications, such as cooling electronic devices and nuclear reactors during emergency shutdowns and improving oil recovery, the micropolar nanofluids' principle has attracted considerable interest in the last few decades. Unsteady free convective MHD flow of a nanofluid through the porous medium analytically enclosed in a rotating frame by a moving vertical permeable flat plate with BC's invariable source and convection was demonstrated by Mabood et al. [19].

There are many examples of micropolar nanofluid flows applicable to realistic applications, such as thin-vessel biological fluid flows, filament suspensions, liquid crystals, slurries, colloidal fluids, exotic lubricants, etc. Extensive reviews of the theory and its applications can be found in [20-21]. Rafique et al. [22] have studied the magnetic field effects on a nanofluid's free convection flow past a semi-infinite vertical flat plate using a numerical technique. Different types of nanoparticles were examined. Shah et al. [23] have studied the turbulent hydro-magnetic radiative flow of a nanofluid past a flat ramp temperature plate.

In the above literature, irreversibility analysis in water and ethylene glycol-based micropolar ferrofluid along thermal radiation over a shrinking sheet has not been studied previously. Thus, it is the major goal of the present study. The micropolar nanofluids consist of the base fluid, pure water, and ethylene glycol with $\mathrm{Fe}_{3} \mathrm{O}_{4}$ nanoparticles. The governing boundary layer dimensionless equations were transformed into ordinary differential equations by appropriated similarity variables. The numerical solution of the present problem is obtained by the Runge-Kutta method followed by the shooting technique. The effects of physical 
parameters of the fluid velocity and temperature are shown graphically. New insights from this study will be useful in several areas of nanotechnology and nanostructure.

\section{Materials and Methods}

\subsection{Mathematical formulation.}

A two-dimensional steady flow of micropolar nanofluid with heat transfer and thermal radiation with heat source over a porous shrinking sheet is considered (see Fig.1). The shrinking velocity of the sheet is $u_{w}=-c x$ where $c$ is the shrinking constant such that $c>0$. The micropolar nanofluids consist of the base fluid, pure water, and ethylene glycol with $\mathrm{Fe}_{3} \mathrm{O}_{4}$ nanoparticles (Table 1). The equations of motion for the micropolar nanofluid and heat transfer under the boundary layer approximation are as follows:

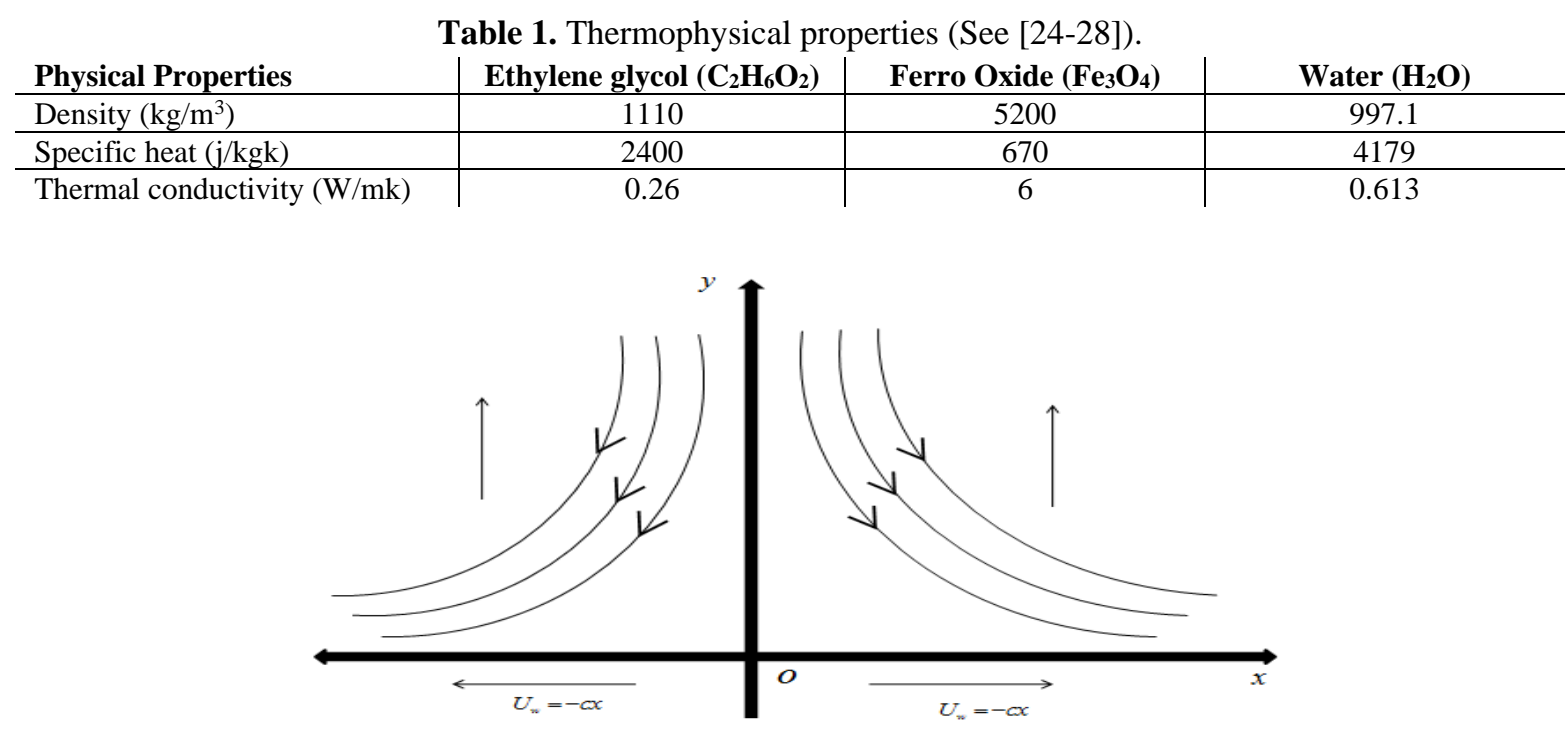

Figure 1. Schematic nanofluid flow model.

The equations of the flow problem are defined as:

$\frac{\partial u}{\partial x}+\frac{\partial u}{\partial y}=0$

$\rho_{n f}\left(u \frac{\partial u}{\partial x}+v \frac{\partial u}{\partial y}\right)=\left(\mu_{n f}+\kappa^{*}\right) \frac{\partial^{2} u}{\partial y^{2}}+\kappa^{*} \frac{\partial N}{\partial y}+g \beta_{n f}\left(T-T_{\infty}\right)$

$\rho_{n f} j\left(u \frac{\partial N}{\partial x}+v \frac{\partial N}{\partial y}\right)=\gamma_{n f} \frac{\partial^{2} N}{\partial y^{2}}-\kappa^{*}\left(2 N+\frac{\partial u}{\partial y}\right)$

$\left(\rho C_{p}\right)_{n f}\left(u \frac{\partial T}{\partial x}+v \frac{\partial T}{\partial y}\right)=\kappa_{n f} \frac{\partial^{2} T}{\partial y^{2}}-\frac{\partial q_{r}}{\partial y}+Q^{*}\left(T-T_{\infty}\right)$

Subject to the boundary conditions

$$
\left.\begin{array}{c}
u=-u_{w}=-c x, v=v_{w}, N=-m \frac{\partial u}{\partial y}, T=T_{w} \text { at } y=0 \\
u \rightarrow 0, N \rightarrow 0, T \rightarrow T_{\infty} \text { as } y \rightarrow \infty
\end{array}\right\}
$$

The $x y$-plane, $T_{w}$ and $T_{\infty}$ both are assumed to be constant. Here, $v_{w}<0$ for mass suction and $v_{w}>0$ for mass injection. We assume that the spin gradient viscosity $\gamma_{n f}$ : 


$$
\gamma_{n f}=\left(\mu_{n f}+\frac{\kappa^{*}}{2}\right) j=\mu_{n f}\left(1+\frac{K}{2}\right) j
$$

The density $\rho_{n f}$, dynamic viscosity $\mu_{n f}$, heat capacitance $\left(\rho C_{P}\right)_{n f}$, kinematic viscosity $v_{f}$ of the base fluid, and thermal conductivity $\kappa_{n f}$ of the nanofluid are defined as follows:

$$
\begin{gathered}
\mu_{n f}=\frac{\mu_{f}}{(1-\phi)^{2.5}}, \rho_{n f}=(1-\phi)_{\rho f}+\phi \rho_{s},\left(\rho C_{P}\right)_{n f}=(1-\phi)\left(\rho C_{P}\right)_{f}+\phi\left(\rho C_{P}\right)_{s}, \\
\kappa_{n f}=\kappa_{f}\left[\frac{\kappa_{s}+2 \kappa_{f}-2 \phi\left(\kappa_{f}-\kappa_{s}\right)}{\kappa_{s}+2 \kappa_{f}+\phi\left(\kappa_{f}-\kappa_{s}\right)}\right]
\end{gathered}
$$

The radiative heat flux is denoted by $q_{r}$.

$\frac{\partial q_{r}}{\partial y}=-\frac{16 \sigma T_{\infty}^{3}}{3 k_{1}} \frac{\partial^{2} T}{\partial y^{2}}$

Now Eq. (4) reduces to:

$u \frac{\partial T}{\partial x}+v \frac{\partial T}{\partial y}=\frac{\kappa_{n f}}{\left(\rho C_{p}\right)_{n f}} \frac{\partial^{2} T}{\partial y^{2}}+\frac{16 \sigma T_{\infty}^{3}}{3 k_{1}\left(\rho C_{p}\right)_{n f}} \frac{\partial^{2} T}{\partial y^{2}}+\frac{Q^{*}}{\left(\rho C_{p}\right)_{n f}}\left(T-T_{\infty}\right)$

The following transforms are introduced:

$\psi=\sqrt{c v_{f}} x f(\eta), N=c x \sqrt{\frac{c}{v_{f}}} h(\eta), T=T_{\infty}+\left(T_{w}-T_{\infty}\right) \theta(\eta)$ and $\eta=\sqrt{\frac{c}{v_{f}}} y$

where $u=\frac{\partial \psi}{\partial y}, v=-\frac{\partial \psi}{\partial x}$. Now Eq. (1) and the Eqns. (2), (3) and (9) reduced to the equations:

$\left(K+(1-\phi)^{-2.5}\right) f^{\prime \prime \prime}+\phi_{1} f f^{\prime \prime}-\phi_{1} f^{\prime 2}+K h^{\prime}+G r \phi_{2}=0$

$(1+0.5 K)(1-\phi)^{-2.5} h^{\prime \prime}+\phi_{1} f h^{\prime}-\phi_{1} h f^{\prime}-K\left(2 h+f^{\prime \prime}\right)=0$

$\left(4+3 R \phi_{4}\right) \theta^{\prime \prime}+3 R \operatorname{Pr} Q \theta+3 R \operatorname{Pr} \phi_{3} f \theta^{\prime}=0$

The transformed boundary conditions are:

$f(\eta)=S, f^{\prime}(\eta)=-1, h(\eta)=-m f^{\prime \prime}(\eta), \theta(\eta)=1$ at $\eta=0$

$f^{\prime}(\eta) \rightarrow 0, h(\eta) \rightarrow 0, \theta(\eta) \rightarrow 0$ as $\eta \rightarrow \infty$

The non-dimensional quantities are:

$$
\begin{aligned}
& G r=\frac{g \beta_{f}\left(T_{W}-T_{\infty}\right)}{c u_{w}}, \operatorname{Pr}=\frac{\mu_{f}\left(C_{P}\right)_{f}}{\kappa_{f}}, Q=\frac{Q^{*}}{c(\rho C p)_{f}}, R=\frac{\kappa_{f} k_{1}}{4 \sigma T_{\infty}^{3}} \\
& \phi_{1}=(1-\phi)+\phi\left(\frac{\rho_{s}}{\rho_{f}}\right), \phi_{2}=(1-\phi)+\phi\left[\frac{(\rho \beta)_{s}}{(\rho \beta)_{f}}\right], \phi_{3}=(1-\phi)+\phi\left[\frac{\left(\rho C_{P}\right)_{s}}{\left(\rho C_{P}\right)_{f}}\right], \phi_{4}=\frac{\kappa_{n f}}{\kappa_{f}}
\end{aligned}
$$

The physical quantities of this study are $C_{f}, C_{n}$ and $N u_{x}$ 


$$
\begin{aligned}
& \tau_{w}=\left[\left(\mu_{n f}+\kappa^{*}\right) \frac{\partial u}{\partial y}+\kappa^{*} N\right]_{y=0}, C_{f}=\frac{\tau_{w}}{\rho_{n f} u_{w}^{2}}=C_{f}=\frac{\phi_{1}+(1-n) K}{\phi_{2}} f^{\prime \prime}(0), \\
& C_{n}=\frac{x}{c}\left(\frac{\partial N}{\partial y}\right)_{y=0}=\operatorname{Re}_{x}^{-1} C_{n}=N^{\prime}(0), \\
& q_{w}=\kappa_{n f}\left(-\frac{\partial T}{\partial y}\right)_{y=0}-\frac{4 \sigma}{k_{1}}\left(-\frac{\partial T^{4}}{\partial y}\right)_{y=0}, N u_{x}=\frac{x q_{w}}{\kappa_{n f}\left(T_{w}-T_{\infty}\right)}=\operatorname{Re}_{x}^{-1 / 2} N u_{x}=-\left(4+3 R \phi_{4}\right) \theta^{\prime}(0)
\end{aligned}
$$

\section{Results and Discussion}

A two-dimensional steady flow of micropolar $\mathrm{Fe}_{3} \mathrm{O}_{2}$-nanofluid over a Shrinking sheet with a heat source is considered. The thermal radiation was taken into account. The governing differential equations were solved numerically, using the Runge-Kutta fourth-order method followed by the shooting technique. We now proceed with the discussion of flow and heat transfer through characteristics in various physical situations of a material parameter $(\mathrm{K})$, thermal Grashof number $(G r)$, wall mass transfer parameter $(S)$, radiation parameter $(R)$, and heat source parameter $(Q)$. Figs. 2-7 present the velocity distribution, Figs. 8 and 11 present the angular velocity, and Fig. 12 present the temperature distribution along with the various physical parameters.

Fig. 2 exhibits the velocity profiles for different values of volumetric fraction parameter; the velocity decreases for increasing the values of a volumetric fraction. It is due to the fact that an increase in the volume fraction improves the density of the nanofluid, and it causes to slow down the fluid velocity. Further, we also observe that the $\mathrm{Fe}_{3} \mathrm{O}_{4}-\mathrm{C}_{2} \mathrm{H}_{6} \mathrm{O}_{2}$ nanofluid exhibits relatively less velocity than the $\mathrm{Fe}_{3} \mathrm{O}_{4}-\mathrm{H}_{2} \mathrm{O}$ nanofluid in the velocity profile. This figure illustrates good agreement with physical behavior. The profile is initiated from a negative value satisfying the boundary surface condition and then tends to zero asymptotically.

The effects of thermal Grashof number on the velocity profile shown in Fig. 3. It is found that the parameter $G r$ signifies the relative influence of thermal buoyancy force and viscous force in the boundary layer regime. It is also seen that the velocity of both Ferro water and ethylene glycol nanofluids increases with the increase in $G r$. This means that the buoyancy force accelerates the velocity field. This gives rise to an increase in the induced flow transport. Figs. 4 and 5 present the effect of the material parameter $(K)$ on the dimensionless velocity and angular velocity distributions. It is found that the velocity increases for an increase of material parameter, and the angular velocity is decreased for both nanofluids from Fig.5. Figs. 6and 7 illustrate the effect of the various values of heat source parameters on the velocity and angular velocity profiles. It is observed that the nanofluid velocity is increased for increasing heat source parameters, but the reverse effect occurs in angular velocity.

The variation of wall suction parameter in velocity and angular velocity profiles is remarked in Figs. 8 and 9. From Fig. 8, the fluid velocity is increased when the increase of wall suction parameter $(\mathrm{m})$. One peculiar case that arises in angular velocity is shown in Fig. 9 when $\mathrm{m}=0$, the profile is linear and linear to the flow direction. The angular velocity is decelerating when increasing the suction parameter.

The influence of wall mass suction parameter $S$ on the velocity profile is shown in Fig.10. It is seen that the velocity magnitude increases with an increase in S. The temperature profiles for different values of S and Q for both nanofluids are presented in Figs. 11 and 12, respectively. It is seen that the fluid temperature decreases with an increase in the heat source 
parameter and S. It is interesting to note that water-based Ferro nanofluid is having more thermal conductivity rather than ethylene glycol-based Ferro nanofluid.

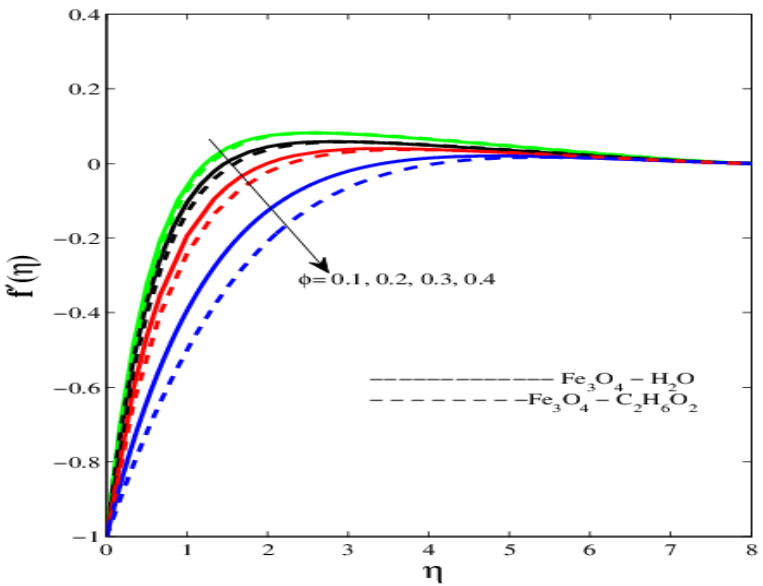

Figure 2. Velocity profiles for different values of $\phi$

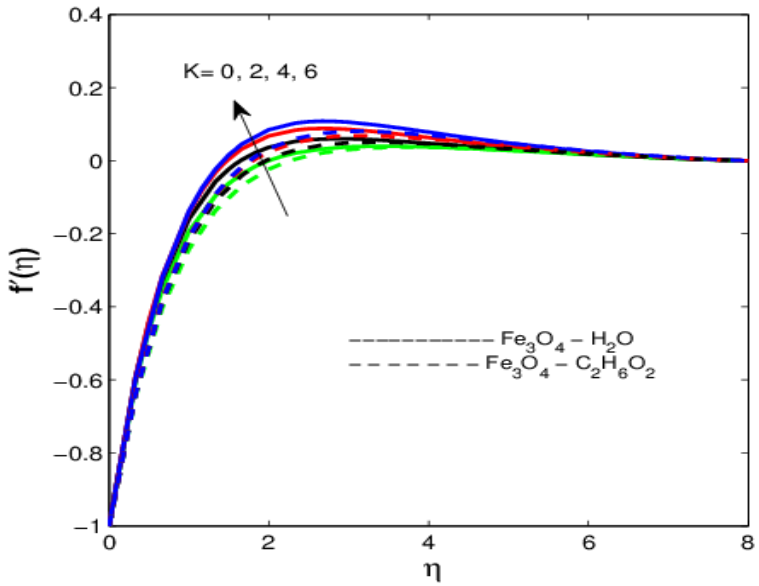

Figure 4. Velocity profiles for different values of $K$

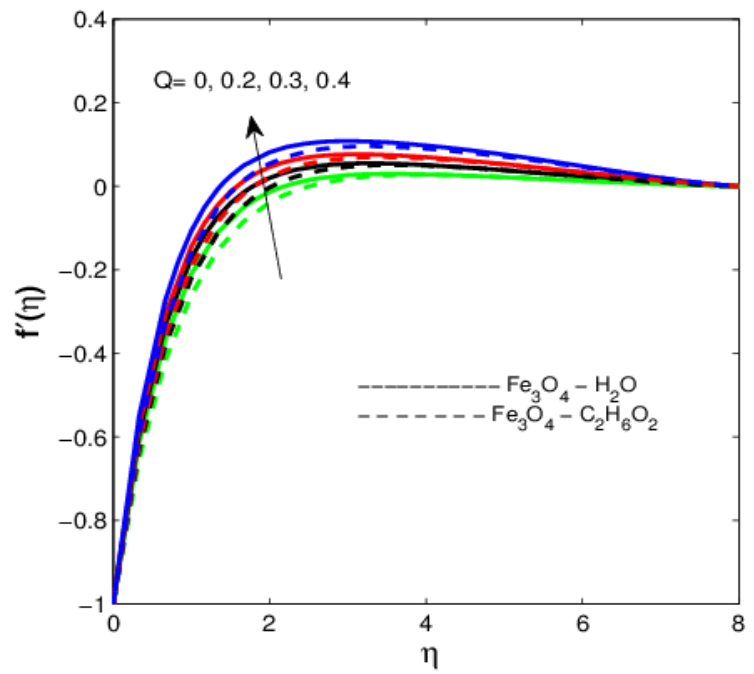

Figure 6. Velocity profiles for different values of $Q$

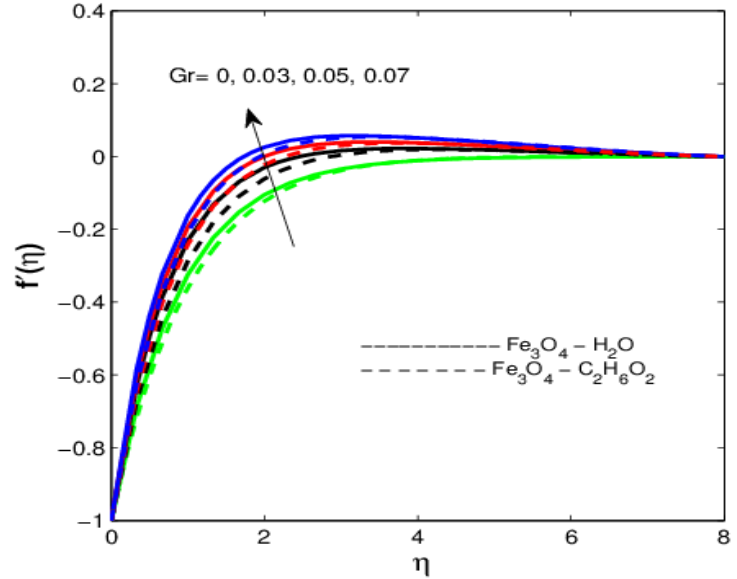

Figure 3. Velocity profiles for different values of $\mathrm{Gr}$

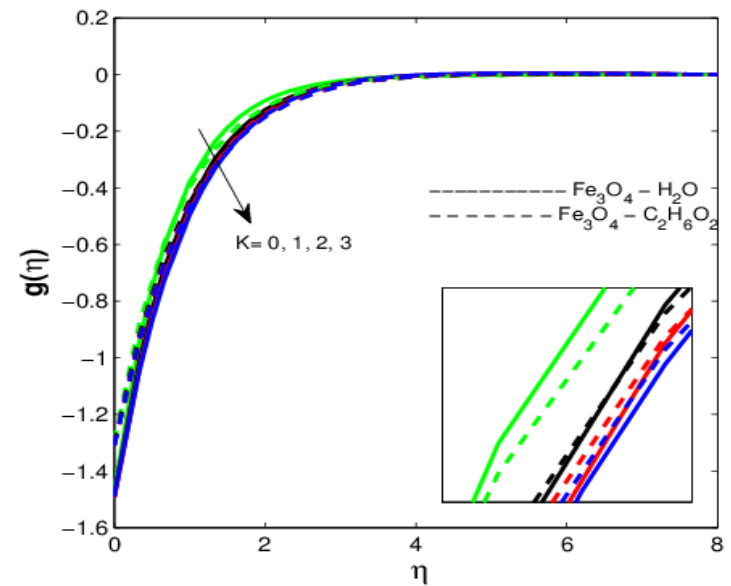

Figure 5. Angular velocity profiles for different values of $K$

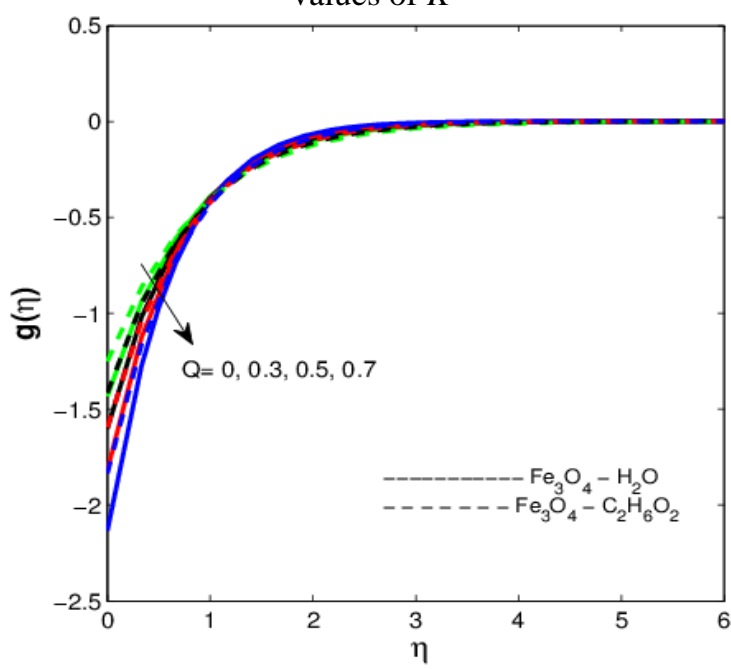

Figure 7. Angular velocity profiles for different values of $Q$ 


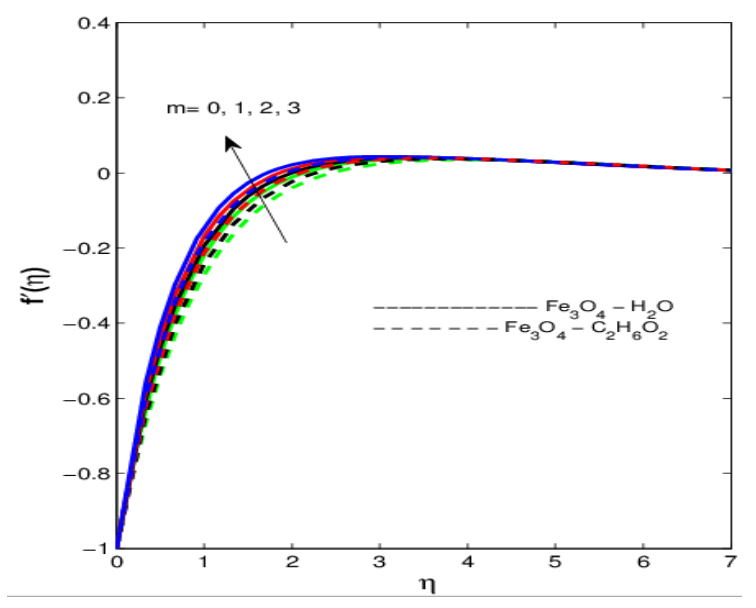

Figure 8. Velocity profiles for different values of $m$

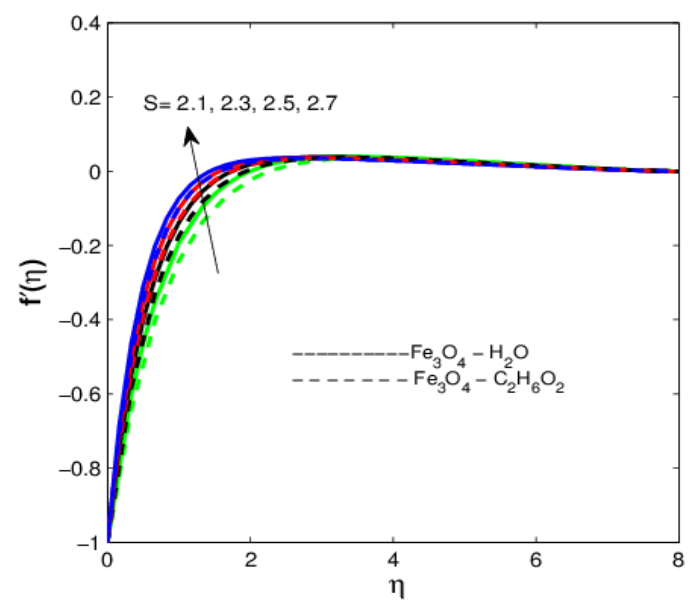

Figure 10. Velocity profiles for different values of $Q$

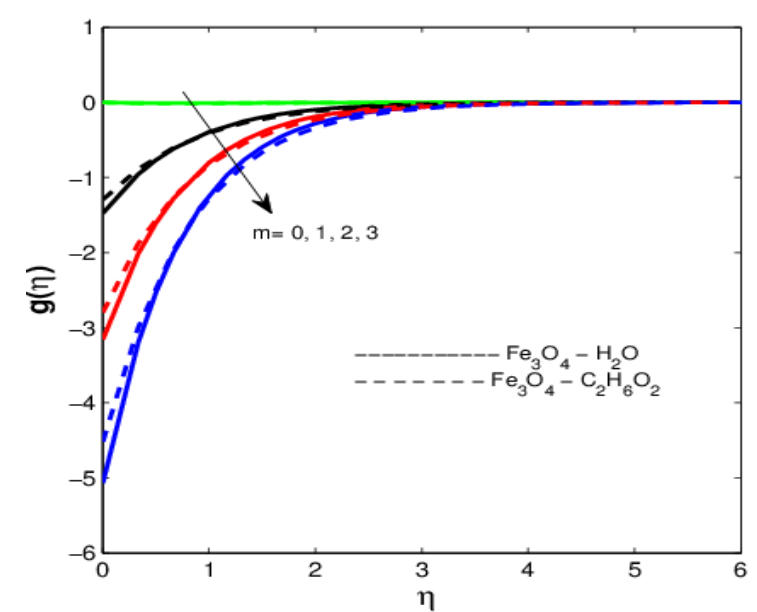

Figure 9. Angular velocity profiles for different values of $m$

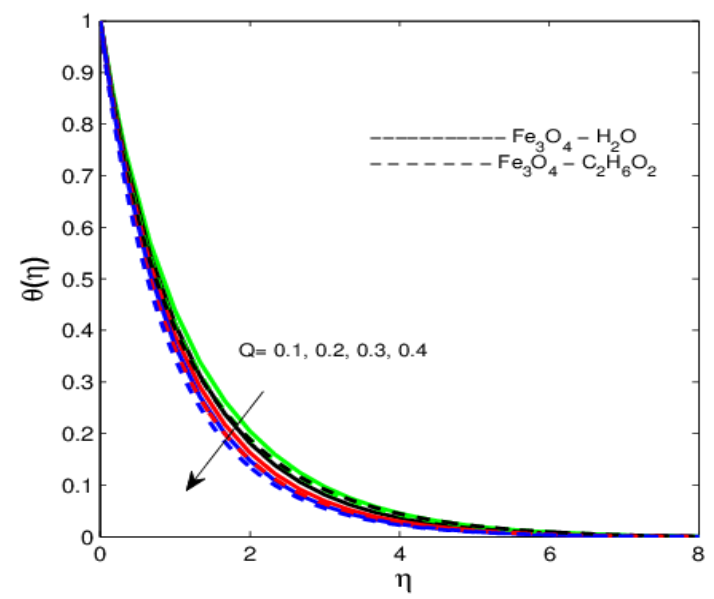

Figure 11. Temperature profiles for differen values of $Q$

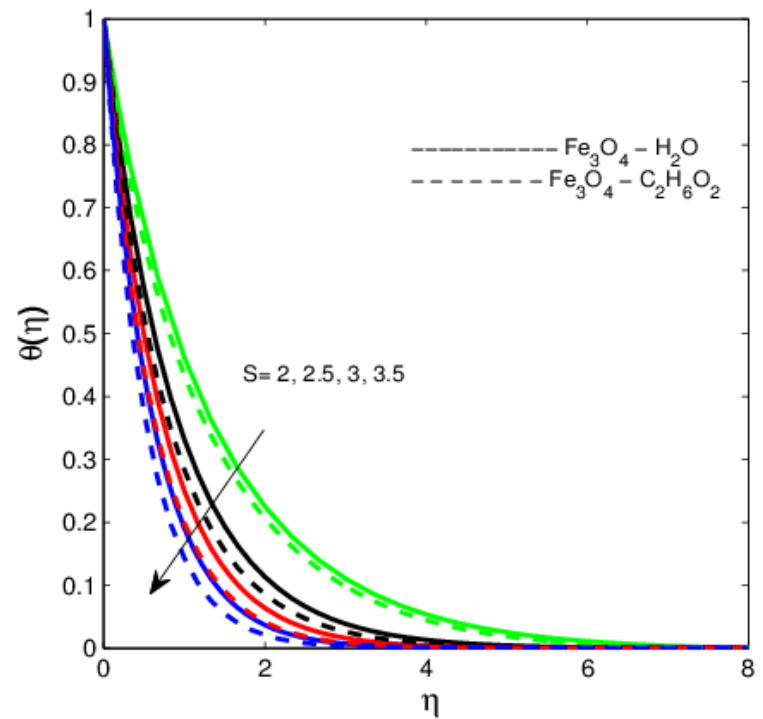

Figure 12. Temperature profiles for different values of $S$

Finally, the typical variable, local skin fraction calculation in terms of $f^{\prime \prime}(0)$ local Nusselt number, i.e., wall temperature gradient and couple stress coefficient $h^{\prime}(0)$ for various parameters, are shown in table 2.

Table 2 contributes the following facts regarding skin friction: The material parameter $\mathrm{K}$ increases the skin friction, but the reverse trend is well marked in couple stress. The peculiarity arises in skin friction, couple stress, and Nusselt number in the case of the increasing value of volume fraction parameter. It is seen from the table that skin friction and Nusselt 
number increases with an increase of radiation parameter. It is observed that $\mathrm{m}$ increases the skin friction is increase. When increasing the heat source parameter, the Nusselt number is increasing.

Table 2. Skin friction $f^{\prime \prime}(0)$, Couple stress $h^{\prime}(0)$, and Nusselt number $-\theta^{\prime}(0)$.

\begin{tabular}{|c|c|c|c|c|c|c|c|}
\hline \multirow{2}{*}{\multicolumn{2}{|c|}{ Parameters }} & \multicolumn{2}{|c|}{$f^{\prime \prime}(0)$} & \multicolumn{2}{|c|}{$h^{\prime}(0)$} & \multicolumn{2}{|c|}{$-\theta^{\prime}(0)$} \\
\hline & & $\mathrm{Fe}_{3} \mathrm{O}_{4}-\mathrm{H}_{2} \mathrm{O}$ & $\mathrm{Fe}_{3} \mathrm{O}_{4}-\mathrm{C}_{2} \mathrm{H}_{6} \mathrm{O}_{2}$ & $\mathrm{Fe}_{3} \mathrm{O}_{4}-\mathrm{H}_{2} \mathrm{O}$ & $\mathrm{Fe}_{3} \mathrm{O}_{4}-\mathrm{C}_{2} \mathrm{H}_{6} \mathrm{O}_{2}$ & $\mathrm{Fe}_{3} \mathrm{O}_{4}-\mathrm{H}_{2} \mathrm{O}$ & $\mathrm{Fe}_{3} \mathrm{O}_{4}-\mathrm{C}_{2} \mathrm{H}_{6} \mathrm{O}_{2}$ \\
\hline \multirow{3}{*}{$K$} & 0 & 1.475 & 1.295 & 1.945 & 1.481 & & \\
\hline & 1 & 1.487 & 1.304 & 1.673 & 1.432 & & \\
\hline & 2 & 1.494 & 1.311 & 1.593 & 1.307 & & \\
\hline \multirow{3}{*}{$Q$} & 0.1 & & & & & 0.060 & 0.055 \\
\hline & 0.2 & & & & & 0.141 & 0.124 \\
\hline & 0.3 & & & & & 0.244 & 0.209 \\
\hline \multirow{3}{*}{ M } & 0 & 1.378 & 1.196 & & & & \\
\hline & 1 & 1.475 & 1.295 & & & & \\
\hline & 2 & 1.579 & 1.398 & & & & \\
\hline \multirow{3}{*}{$\mathrm{R}$} & 0 & 1.350 & 1.145 & & & -0.125 & -0.125 \\
\hline & 0.1 & 1.475 & 1.295 & & & 0.060 & 0.055 \\
\hline & 0.2 & 1.502 & 1.321 & & & 0.063 & 0.055 \\
\hline \multirow{3}{*}{$\phi$} & 0 & 1.969 & 1.969 & 3.120 & 3.120 & 0.056 & 0.056 \\
\hline & 0.01 & 1.992 & 1.980 & 3.209 & 3.170 & 0.057 & 0.056 \\
\hline & 0.02 & 2.011 & 1.987 & 3.288 & 3.210 & 0.057 & 0.056 \\
\hline
\end{tabular}

\section{Conclusions}

The numerical solution is obtained for the free convective flow of water/ethylene glycol-based micropolar nanofluid over a heat source shrinking sheet. The effects of the material parameter, thermal Grashof number, wall mass transfer parameter, radiation parameter, and heat source parameter are examined. The result shows that skin friction increases with an increase in material parameter, wall mass transfer parameter, radiation, and nanoparticles volume fraction. The heat transfer rate increases with an increase in heat source parameter, radiation, and nanoparticles volume fraction.

\section{Funding}

This research received no external funding.

\section{Acknowledgments}

The authors would like to thank the anonymous reviewers for their valuable comments and suggestions to improve the paper's quality.

\section{Conflicts of Interest}

The authors declare no conflict of interest.

\section{References}

1. Akilu, S.; Narahari, M. Effects of heat generation or absorption on free convection flow of a nanofluid past an isothermal inclined plate. Advanced Materials Research 2014, 97, 267-271, https://doi.org/10.4028/www.scientific.net/amr.970.267.

2. Akmal, N.; Sagheer, M.; Hussain, S.; Kamran, A. Investigation of free convection in micropolar nanofluid with induced magnetic field. The European Physical Journal Plus 2019, 134, https://doi.org/10.1140/epjp/i2019-12512-7. 
3. Bhargava, R.; Rani, M. Numerical solution of heat transfer in micropolar fluid flow in a channel with porous walls. International Journal of Engineering Science 1985, 23, 409-413, https://doi.org/10.1016/00207225(85)90088-6.

4. Borrelli, A.; Giantesio, G.; Patria, M.C. Magnetoconvection of a micropolar fluid in a vertical channel. International Journal of Heat and Mass Transfer 2015, 80, 614-625, https://doi.org/10.1016/j.ijheatmasstransfer.2014.09.031.

5. Chamkha, J.; Aly, A.M. MHD free convection flow of a nanofluid past a vertical plate in the presence of heat generation or absorption effects. Chemical Engineering Communications 2010, 198, 425-441, https://doi.org/10.1080/00986445.2010.520232.

6. Cheng, C. Natural convection boundary layer flow of a micropolar fluid over a vertical permeable cone with variable wall temperature. International Communications in Heat and Mass Transfer 2011, 38, 429-433, https://doi.org/10.1016/j.icheatmasstransfer.2010.12.021.

7. Choi, S.U.S.; Eastman, J.A. Enhancing thermal conductivity of fluids with nanoparticles. Int Mech Eng Congress and Exposition. San Francisco USA FED 231/MD 1995, 66, 99-105.

8. Das, K. Influence of thermophoresis and chemical reaction on MHD micropolar fluid flow with variable fluid properties. International Journal of Heat and Mass Transfer 2012, 55, 7166-7174, https://doi.org/10.1016/j.ijheatmasstransfer.2012.07.033

9. Das, S.K.; Choi, S.U.S.; Patel, H.E. Heat Transfer in Nanofluids-A Review. Heat Transfer Engineering 2006, 27, 3-19, https://doi.org/10.1080/01457630600904593.

10. Eringen, A.C. Theory of micropolar fluids. Indiana University Mathematics Journal 1996, 16, 1-18, https://doi.org/10.1512/iumj.1967.16.16001.

11. Fakour, M.; Vahabzadeh, A.; Ganji, D.D.; Hatami, M. Analytical study of micropolar fluid flow and heat transfer in a channel with permeable walls. Journal of Molecular Liquids 2015, 204, 198-204, https://doi.org/10.1016/j.molliq.2015.01.040.

12. Ibrahim, W.; Gadisa, G. Non-linear convective boundary layer flow of micropolar-couple stress nanofluids past permeable stretching sheet using Cattaneo-Christov heat and mass flux model. Heat Transfer 2020, 49, 2521-2550, https://doi.org/10.1002/htj.21733.

13. Ishak, A.; Nazar, R.; Pop, I. Boundary-layer flow of a micropolar fluid on a continuously moving or fixed permeable surface. International Journal of Heat and Mass Transfer 2007, 50, 4743-4748, https://doi.org/10.1016/j.ijheatmasstransfer.2007.03.034.

14. Kamran, M. Heat source/sink and Newtonian heating effects on convective micropolar fluid flow over a stretching/shrinking sheet with slip flow model. International Journal of Heat and Technology 2018, 36, 473-482, https://doi.org/10.18280/ijht.360212.

15. Khan, W.A.; Rashad, A. M.; EL-Kabeir, S.M.M.; EL-Hakiem, A.M.A. Framing the MHD micropolar nanofluid flow in natural convection heat transfer over a radiative truncated cone. Processes 2020, 8, https://doi.org/10.3390/pr8040379.

16. Khan, W.A.; Khan, Z.H.; Qasim, M. MHD fluid flow and heat transfer of micropolar ferrofluids over a stretching sheet. Journal of Nanofluids 2016 5, 567-573, https://doi.org/10.1166/jon.2016.1235.

17. Kumar, T.S.; Kumar, B.R.; Makinde, O.D.; Kumar, A.G.V. Magneto-convective heat transfer in micropolar nanofluid over a stretching sheet with non-uniform heat source/sink. Defect and Diffusion Forum 2018, 387, 78-90, https://doi.org/10.4028/ www.scientific.net/ddf.387.78.

18. Kumaresan, E.; Kumar, A.G.V. Chemically reactive 3D non-linear magneto hydrodynamic rotating flow of nanofluids over a deformable surface with joule heating through porous medium. Trends in Mathematics 2019, 313-323, https://doi.org/10.1007/978-3-030-01123-9_31.

19. Mabood, F.; Ibrahim, S.M.; Rashidi, M.M.; Shadloo, M.S.; Lorenzini, G. Non-uniform heat source/sink and Soret effects on MHD non-Darcian convective flow past a stretching sheet in a micropolar fluid with radiation. International Journal of Heat and Mass Transfer 2016, 93, 674-682, https://doi.org/10.1016/j.ijheatmasstransfer.2015.10.014.

20. Naveed Khan, M.; Nadeem, S.; Muhammad, N. Micropolar fluid flow with temperature-dependent transport properties. Heat Transfer 2020, 49, 2375-2389, https://doi.org/10.1002/htj.21726.

21. Pal, D.; Mandal, G. Thermal radiation and MHD effects on boundary layer flow of micropolar nanofluid past a stretching sheet with non-uniform heat source/sink. International Journal of Mechanical Sciences 2017, 126, 308-318, https://doi.org/10.1016/j.ijmecsci.2016.12.023.

22. Rafique, K.; Anwar, M.I.; Misiran, M.; Asjad, M.I. Energy and mass transport of micropolar nanofluid flow over an inclined surface with Keller-Box simulation. Heat Transfer 2020, 49, 4592-4611, https://doi.org/10.1002/htj.21843.

23. Shah, Z.; Alzahrani, E.O.; Dawar, A.; Ullah, A.; Khan, I. Influence of cattaneo-christov model on DarcyForchheimer flow of micropolar ferrofluid over a stretching/shrinking sheet. International Communications in Heat and Mass Transfer 2020, 110, 104385, https://doi.org/10.1016/j.icheatmasstransfer.2019.104385.

24. Subhani, M.; Nadeem, S. Numerical analysis of 3D micropolar nanofluid flow induced by an exponentially stretching surface embedded in a porous medium. The European Physical Journal Plus 2017, 132, https://doi.org/10.1140/epjp/i2017-11660-0. 
25. Kumar T.S. Impact of Lorentz force on free convection flow of a viscous fluid past an infinite vertical plate. SN Applied Sciences 2019, 1, 1-14, https://doi.org/10.1007/s42452-019-1292-8.

26. Kumar, T. S.; Dinesh, P.A.; Makinde, O.D. Impact of Lorentz force and viscous dissipation on unsteady nanofluid convection flow over an exponentially moving vertical plate. Mathematical Models and Computer Simulations 2020, 12, 631-646, https://doi.org/10.1134/s2070048220040110.

27. Tabassum, R.; Mehmood, R.; Akbar, N.S. Magnetite micropolar nanofluid non-aligned MHD flow with mixed convection. European Physical Journal Plus 2017, 132, https://doi.org/10.1140/epjp/i2017-11537-2.

28. Tiwari, A.; Shah, P.D.; Chauhan, S.S. Analytical study of micropolar fluid flow through porous layered micro vessels with heat transfer approach. European Physical Journal Plus 2020, 135, 1-15, https://doi.org/10.1140/epjp/s13360-020-00128-x. 